\title{
Using Nodal Infection Risks to Guide Interventions Following Accidental Intrusion due to Sustained Low Pressure Events in a Drinking Water Distribution System
}

\author{
Fatemeh Hatam ${ }^{1, *}$, Mirjam Blokker ${ }^{2} \mathbb{D}$, Marie-Claude Besner ${ }^{3}$, Gabrielle Ebacher 4 \\ and Michèle Prévost ${ }^{1}$ \\ 1 NSERC Industrial Chair in Drinking Water, Department of Civil, Geological and Mining Engineering, \\ Polytechnique Montréal, CP 6079, Succ. Centre-ville, Montréal, QC H3C 3A7, Canada \\ 2 KWR Watercycle Research Institute, Groningenhaven 7, 3433 PE Nieuwegein, The Netherlands \\ 3 R\&D Engineer, Water Service, City of Montreal, Montréal, QC H3C 6W2, Canada \\ 4 Technical Engineer, Environment Service, Drinking Water Division, City of Laval, QC H7V 3Z4, Canada \\ * Correspondence: fatemeh.hatam@polymtl.ca; Tel.: +1-514-340-4711 (ext. 2983)
}

Received: 10 June 2019; Accepted: 28 June 2019; Published: 3 July 2019

\begin{abstract}
Improving the risk models to include the possible infection risk linked to pathogen intrusion into distribution systems during pressure-deficient conditions (PDCs) is essential. The objective of the present study was to assess the public health impact of accidental intrusion through leakage points in a full-scale water distribution system by coupling a quantitative microbial risk assessment (QMRA) model with water quality calculations based on pressure-driven hydraulic analysis. The impacts on the infection risk of different concentrations of Cryptosporidium in raw sewage (minimum, geometric mean, mean, and maximum) and various durations of intrusion/PDCs ( $24 \mathrm{~h}, 10 \mathrm{~h}$, and $1 \mathrm{~h}$ ) were investigated. For each scenario, 200 runs of Monte Carlo simulations were carried out to assess the uncertainty associated with the consumers' behavioral variability. By increasing the concentrations of Cryptosporidium in raw sewage from 1 to 560 oocysts/L for a 24-h intrusion, or by increasing the duration of intrusion from 1 to $24 \mathrm{~h}$, with a constant concentration (560 oocysts/L), the simulated number of infected people was increased by 235 -fold and 17 -fold, respectively. On the first day of the 1-h PDCs/intrusion scenario, a 65\% decrease in the number of infected people was observed when supposing no drinking water withdrawals during low-pressure conditions at nodes with low demand available $(<5 \%)$ compared to no demand. Besides assessing the event risk for an intrusion scenario, defined as four days of observation, the daily number of infected people and nodal risk were also modeled on different days, including during and after intrusion days. The results indicate that, for the case of a 1-h intrusion, delaying the start of the necessary preventive/corrective actions for $5 \mathrm{~h}$ after the beginning of the intrusion may result in the infection of up to 71 people.
\end{abstract}

Keywords: QMRA; sustained pressure drops; accidental intrusion; infection risk from Cryptosporidium; pressure-driven hydraulic analysis

\section{Introduction}

Distribution system (DS) deficiencies may play a role in the occurrence of waterborne disease outbreaks [1]. Ageing of pipeline infrastructure is going to become more problematic over time by increasing the probability of experiencing sustained low/negative pressure conditions in the network (pipe breaks), leading to possible intrusion from points of leakage. Assessment of public health risk associated with such type of events may be achieved through modeling. While reliable hydraulic and 
water quality models can be used to simulate ingress of contaminated water and its propagation into a network, the use of quantitative microbial risk assessment (QMRA) models is required to estimate the potential health risk. QMRA and management approaches can contribute in bringing safer water to consumers [2].

Modeling of water quality under pressure deficient conditions. Integration of pressure-driven hydraulic analysis into QMRA models is required for a more accurate risk analysis of water contamination resulting from accidental intrusion under sustained pressure-deficient conditions (PDCs). In such conditions, a reliable estimation of intrusion points, contamination mass rate entering the DS, and fate/transport of contamination through the network cannot be achieved using traditional demand driven-analysis (DDA) models such as EPANET 2 [3]. Pressure-driven analysis (PDA) was coupled to single species water quality modeling to optimize management strategies (e.g., flushing and isolation actions) by minimizing the mass of consumed contaminant [4-6]. A more detailed literature review on hydraulic and water quality modeling under sustained PDCs can be found elsewhere [7].

Applications of QMRA to drinking water DSs. Despite evidence of drinking water DS deficiencies causing infectious waterborne diseases [8,9], the majority of QMRA work has been devoted to assessing risk of drinking water treatment failures [2]. Viñas et al. [10] and Hamouda et al. [11] presented detailed literature reviews on QMRA models applied to microbial contaminants in drinking water DSs. Besner et al. [12] developed a conceptual model to assess the public health risk associated with intrusion events. QMRA models have been applied to real DSs to evaluate the infection risk associated with the presence of viruses resulting from intrusion events caused from transient PDCs [13-15]. Standard QMRA models consider the water is consumed randomly at any time or at fixed times during the day $[14,16,17]$. The timing of water withdrawals for drinking purpose is an important factor when assessing the probability of infection as a result of intrusion events and may not be the same as the timing of the total consumption $[17,18]$. An improved QMRA that integrates the consumer's behavior (probability density functions (PDFs) of the numbers of glasses and the volume consumed, and kitchen tap use) was developed and applied to assess the infection risk associated with contamination after main repairs $[18,19]$. They investigated the impact of different parameters such as the location of contamination and the times of valve openings on the infection risk with various pathogens (Campylobacter, Cryptosporidium, Giardia and rotavirus), in the absence of any disinfectant residual. Schijven et al. [20] also considered consumer behavior to estimate the infection risk from ingestion of contaminated water or inhalation of contaminated aerosol droplets in the case of intentional contamination of different durations and seeding concentrations in a DS.

Improving estimations of the infection risks due to sustained pressure deficient conditions requires numerical approaches that produce realistic estimations of nodal ingress volumes, predictions of propagation throughout the network, and integration of the consumer's behavior during and after pressure losses. Besner et al. [16] emphasized the necessity of performing PDA instead of DDA to simulate the infection risk associated with PDCs in future studies. Besides low pressure, the presence of external contamination and pathways are essential for intrusion to occur [21]. Adjusting the presence of potential pathway for intrusion based on the state of decay of the piping has been proposed [22,23].

The primary objective of this work was to estimate the infection risk associated with accidental intrusion through leakage points into a DS as a result of unplanned sustained low/negative pressure events $(24 \mathrm{~h}, 10 \mathrm{~h}$, and $1 \mathrm{~h})$. To achieve this goal, several original improvements to the various models were made. First, the QMRA model developed by Blokker et al. [18] was customized and linked with water quality calculations based on a pressure-driven hydraulic analysis. Then, the estimated contamination mass rate at each intrusion node was adjusted by the assigned leakage demand (proxy for pipe age and material) and the pressure values during PDCs, computed using PDA. Finally, to better simulate the consumers behavior during low-pressure conditions, the consumption of tap water was adjusted based on demand availability (no demand or $<5 \%$ ) on the infection risk. The secondary objective of this work was to propose a basis for the analysis of risk to guide the definition of areas subjected to a boil water advisory or corrective actions. To achieve this goal, we assessed the potential 
use of the temporal (daily versus event) and spatial distribution of nodal risks to determine the location and the duration of advisories. To the knowledge of the authors, no study so far has quantified the infection risk of accidental intrusion resulting from sustained PDCs, using realistic PDA to adjust intrusion volume for nodal pressure, perform water quality analysis and integrate the impact of demand availability on the consumption during pressure drops.

\section{Methodology}

The QMRA model developed by Blokker et al. [18] was customized to be coupled with water quality calculations based on pressure-driven hydraulic analysis. The model was used to quantify the infection risk associated with accidental intrusion events as a result of sustained PDCs in a full-scale DS. The main steps for risk analysis are exposure analysis and calculation of infection risk. A simplified flow chart of the QMRA steps is illustrated in Figure 1. These steps include: (a) simulating the hydraulic behavior of the network under the intended PDCs to define the intrusion nodes, intrusion flow rates (based on size of opening leaks and pressure differential), and nodes with unsatisfied demand; (b) defining the outside pipe conditions to calculate the potential contaminant mass rate entering the system; (c) modeling fate/transport of ingress microorganisms through network; (d) specifying the microbial exposure (dose) considering consumers' drinking water behavior; and (e) estimating the risk of infection based on dose-response models.

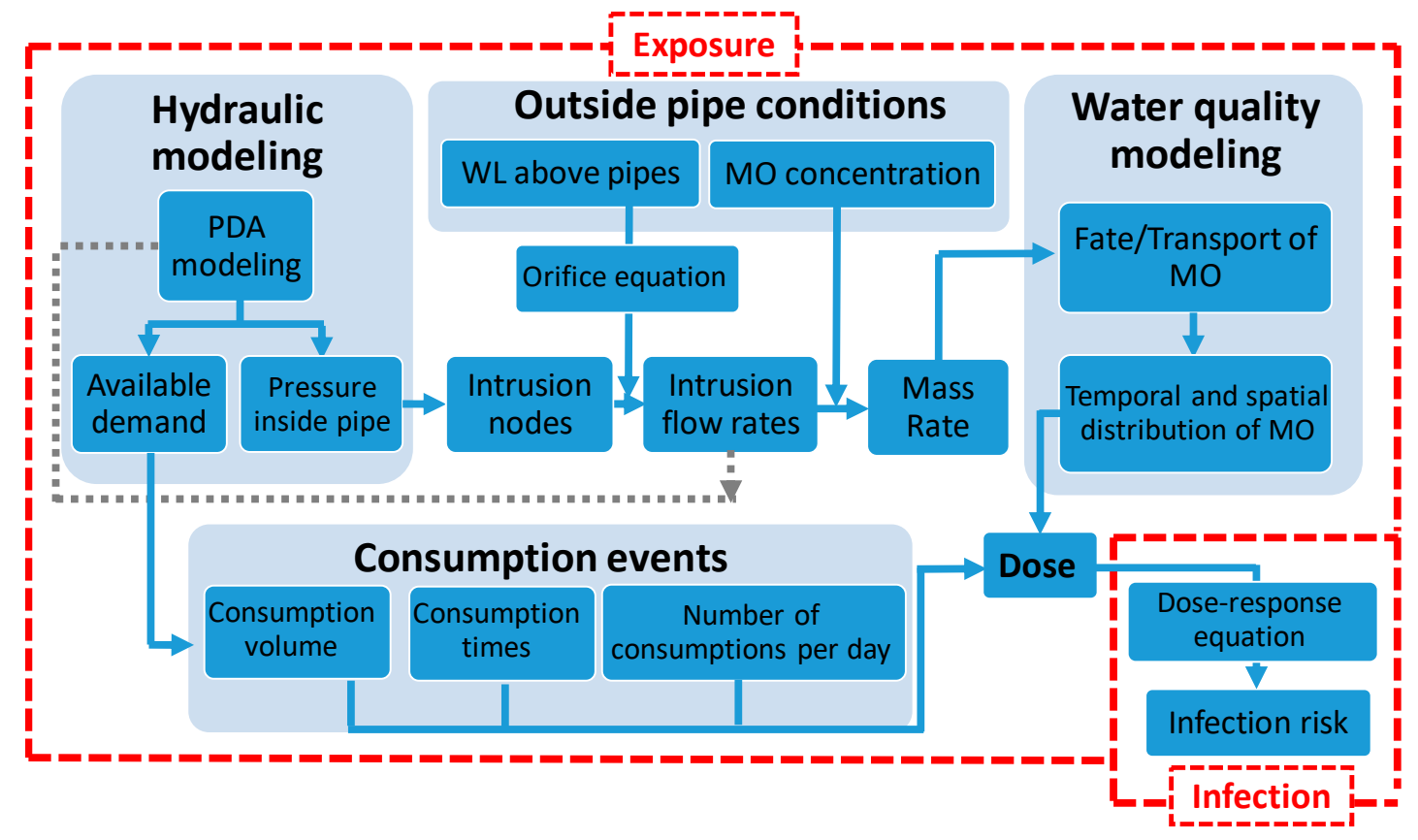

Figure 1. Flowchart for QMRA of accidental intrusion during sustained PDCs; WL, water level; $\mathrm{MO}$, microorganism.

\subsection{Exposure Analysis}

\subsubsection{Hydraulic and Water Quality Analysis}

To estimate the ingested dose, fate/transport of contaminants through the network should first be estimated using appropriate hydraulic and water quality models. Water quality modeling based on PDA was performed using WaterGEMS V8i (SELECTseries 5) [24]. Transport of Cryptosporidium oocysts through the network was simulated over time and, because Cryptosporidium is highly resistant to chlorine disinfection [25], the chlorine decay was not included in the model. Sewage is defined as the source of contamination outside the pipes. Minimum, geometric mean, arithmetic mean, and maximum levels of Cryptosporidium in sewage were assumed to be 1, 6, 26, and 560 oocysts/L, respectively [26]. 
The DS model used in this study includes 30,077 nodes and 3 water treatment plants (WTPs), which serve nearly 400,000 residents. More details on the simulated full-scale network can be found in Hatam et al. [7]. The unplanned shutdown of one WTP was simulated and a $5 \mathrm{~m}$ decrement in the outlet pressure of the two other WTPs was assumed as a result of the flow-rate increase. It should be noted that the two other WTPs might (partially) compensate the shutdown of the other WTP as the entire network is hydraulically interconnected. Following the shutdown duration $(1,10$ or 24 h), the simulation was continued for 3 days to investigate the long-term public health impacts of the accidental intrusion events in this large DS. The impacts of intrusion duration on exposure and, consequently, risk of infection were studied. More details on accidental intrusion modeling can be found in the Supplementary Materials. Nodes with pressure head less than $1 \mathrm{~m}$ were considered as the potential intrusion sites (Figure S4). In the hydraulic model, for the sake of simplicity, the demand is considered constant during the day and equal to the peak hour demand (i.e., 19:00) for the scenarios of 1,10 and $24 \mathrm{~h}$ of PDCs/intrusion. Additional scenario with the daily water consumption pattern in the hydraulic model was studied for the intrusion event resulting from $1 \mathrm{~h}$ PDCs set to start at 18:30.

\subsubsection{Consumption Events}

The temporal concentrations of Cryptosporidium calculated from water quality analysis were then imported into MATLAB (MathWorks, Natick, MA, USA) where the QMRA was performed for exposure assessment and dose-response analysis. Consumption events or consumers' behavior in this study refer to: (1) the volume of consumption; (2) the number of times that one fills a glass; and (3) the times at which the glass is filled from the tap. In the present study, consumption times corresponded to the water use at the kitchen tap as proposed by Blokker et al. [18]. In the simulations, the average kitchen tap use was then modified for each node of the studied network based on the nodal residential demand and the availability of demand, calculated from PDA under PDCs. In this study, the average kitchen tap use for non-residential nodes (about $60 \%$ of the nodes) was set to zero. This differed from Blokker et al. [18], who adjusted the average kitchen tap use at certain times to include zero demand periods identified by detailed residential demand. In this study, to account for demand satisfaction as computed by PDA at each node, the kitchen tap use was set to zero at times when there was no demand available under PDCs (Figure S1). For PDCs with some demand satisfaction, it was assumed that consumers can adjust the filling duration based on the available flow at the tap. If the PDCs did not last for the whole day, the total daily volume of water consumed by each person at the nodes with no demand under PDCs would not be affected. The sensitivity of the results to the demand satisfaction ratio (DSR) was investigated in an additional scenario by fixing the kitchen tap use to zero at the time when there is low $(<5 \%)$ demand available at the nodes. This approach is more realistic as the required time to fill a glass of water at a kitchen tap will increase by more than 20 times when the DSR is less than $5 \%$.

The other important parameter for estimating the risk of exposure to microbial contamination is the volume of water that is ingested per person per day. The number of times each person would fill his/her glass or bottle during a day was estimated using a Poisson distribution. The ingested volume at each filling time was defined by a lognormal distribution. Due to the lack of information for the studied network, the data from Blokker et al. [18] were used for the simulation and more details can be found in their paper.

In this study, the hydraulic and water quality conditions were assumed to be known for each scenario, and 200 runs of Monte Carlo simulations were performed to investigate consumers' behavior. In each Monte Carlo run, the number and times of consumption events as well as the ingested volume for each consumption event were randomly picked for each person every day of the simulation.

In the studied hydraulic model, the total nodal demands could be a combination of different types of demand defined as: residential, commercial, industrial, institutional, municipal or, leakage. In total, 11,194 of the nodes included residential demand. To determine the number of people supplied per node, the residential demand per node was considered and the daily per capita average demand 
was set to $220 \mathrm{~L} /$ person/day. Consequently, only the residential exposure from tap water as a result of the simulated accidental intrusion was investigated (e.g., exposure at school was not considered). More information on the estimation of the number of people at each node and the distribution of population is in the Supplementary Materials. Dose is equal to the number of consumed pathogens and was calculated by multiplying the intake volume by the concentration of pathogens at the time of withdrawal. This step was repeated for all the glasses that a person takes over the simulation duration, which is 1 day for daily risk and 4 days for the event risk. For each person, the total dose was calculated by summing the dose in each glass consumed.

\subsection{Calculation of Infection Risk}

Dose-response analysis was performed to calculate the infection risk for each person resulting from accidental intrusion during sustained PDCs. The computed dose was implemented in the dose-response model employed by Blokker et al. [19] for Cryptosporidium using the median (50th percentile) and maximum (100th percentile) dose-response relationships. The median infection risk is reported everywhere in this study unless otherwise stated.

The calculated infection risks of all the people in the network were summed up and rounded to the nearest integer greater than or equal to the calculated value to estimate the equivalent number of infected people for the simulated event [18]. The number of infected people was calculated either for the whole observation period (4 days) or for each day separately. To calculate the nodal risk, the infection risks corresponding to all the people at the same node were summed up.

\section{Results}

Estimating ingress volumes. Histograms of nodal pressures and demand satisfaction ratios (DSRs: available nodal demand divided by the required demand) using PDA are illustrated in Figure 2. Fewer than $1 \%$ of the nodes (93 nodes) were prone to intrusion as they experienced pressures less than $1 \mathrm{~m}$ under PDCs, which corresponded to the set pressure head above pipes. For about $30 \%$ of the nodes, the pressure was less than or equal to the required pressure value assumed in this study for full demand satisfaction $(15 \mathrm{~m})$. The DSRs for these nodes are shown in Figure $2 \mathrm{~b}$, excluding nodes with no required demand. Figure $2 \mathrm{~b}$ shows that 1103 nodes have a DSR of less than $50 \%$ during depressurization.

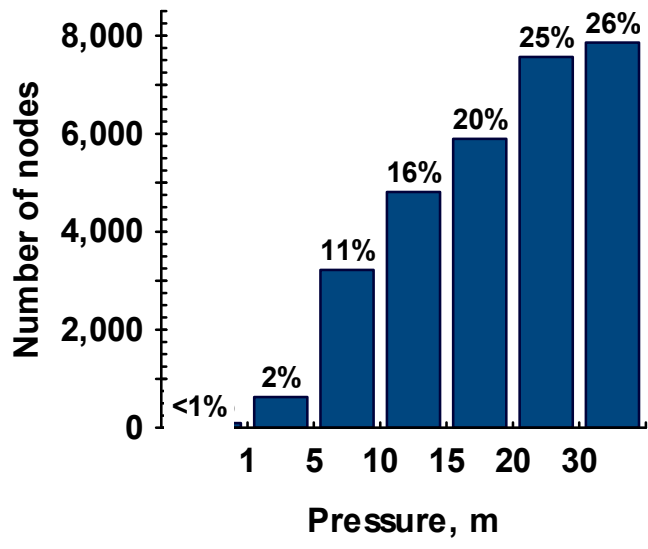

(a)

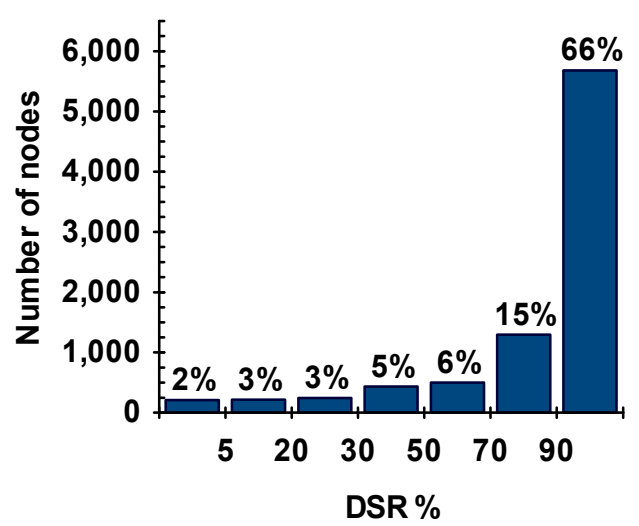

(b)

Figure 2. Distribution of: (a) nodal pressures for the whole network (30,077 nodes); and (b) demand satisfaction ratios (DSRs) for nodes under pressure-deficient conditions (8578 nodes), excluding the nodes with zero demand.

The distribution of intrusion flow rates at the ingress nodes is illustrated in Figure 3. The maximum flow rate was $56 \mathrm{~L} / \mathrm{h}$ and about half of the nodes had an intrusion flow rate less than $5 \mathrm{~L} / \mathrm{h}$. The contaminated water entered the network at a flow rate of $804 \mathrm{~L} / \mathrm{h}$ through all the leakage orifices. 
For the scenarios of 10 and $24 \mathrm{~h}$ PDCs, the intrusion flow rate at each node remained constant during the event because of the use of a constant demand. As the $1 \mathrm{~h}$ event, with daily consumption pattern, was assumed to occur at the peak demand hour, the nodal intrusion flow rates also corresponded to those shown in Figure 3.

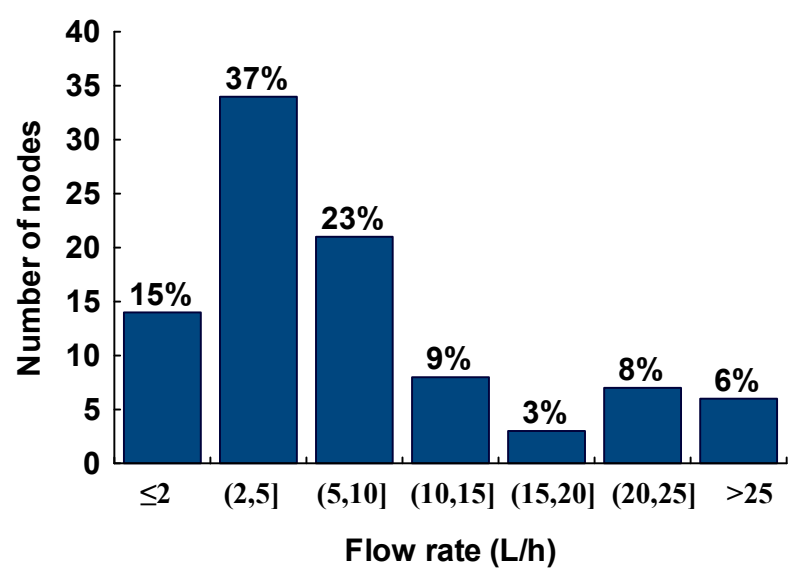

Figure 3. Distribution of nodal intrusion flow rates through 93 leak openings under the simulated pressure-deficient conditions.

Concentrations of pathogens in sewage. To cover different consumption behaviors, 200 Monte Carlo simulations were carried out for each scenario of Cryptosporidium concentration in sewage $(1,6$, 26 , and 560 oocysts/L). The resulting cumulative probability distributions of the number of infected people are plotted in Figure 4. In this figure, the solid lines correspond to the median infection risk, and the dotted lines are the maximum infection risk. For all concentrations, the number of infected people associated to the maximum infection risk was increased by about two folds compared to the median infection risk. For the concentration of 560 oocysts/L, $50 \%$ of the consumption events led to at least 1378 (2652) infected people considering the median (maximum) infection risk. As expected, the number of infected people increased when the Cryptosporidium concentration increases from 1 to 560 oocysts/L.

Consumption behavior. Figure 5 shows the sensitivity of the number of infected people over the four-day observation period to the volume of consumption $(300 \mathrm{~mL}, 500 \mathrm{~mL}$ or $1 \mathrm{~L}$ per day per person) and number of glasses per day $(1,3$, or 10$)$. A total of nine scenarios were considered with a Cryptosporidium concentration of 560 oocysts/L and $24 \mathrm{~h}$ of PDCs. As expected, lower volumes of unboiled tap drinking water per person per day largely reduced the infection risk. By decreasing the volume by half $(500 \mathrm{~mL})$, the number of infected people decreased by $40 \%$; decreasing the volume to $300 \mathrm{~mL}$ reduced the risk further by about $60 \%$. By increasing the number of glasses per day from 1 to 3, 19 more people were likely to be infected for a $300 \mathrm{~mL}$ volume, and this value became 62 for a $1 \mathrm{~L}$ consumption volume per day per person (based on the values of $\mathrm{F}(\mathrm{x})=1$ ). 

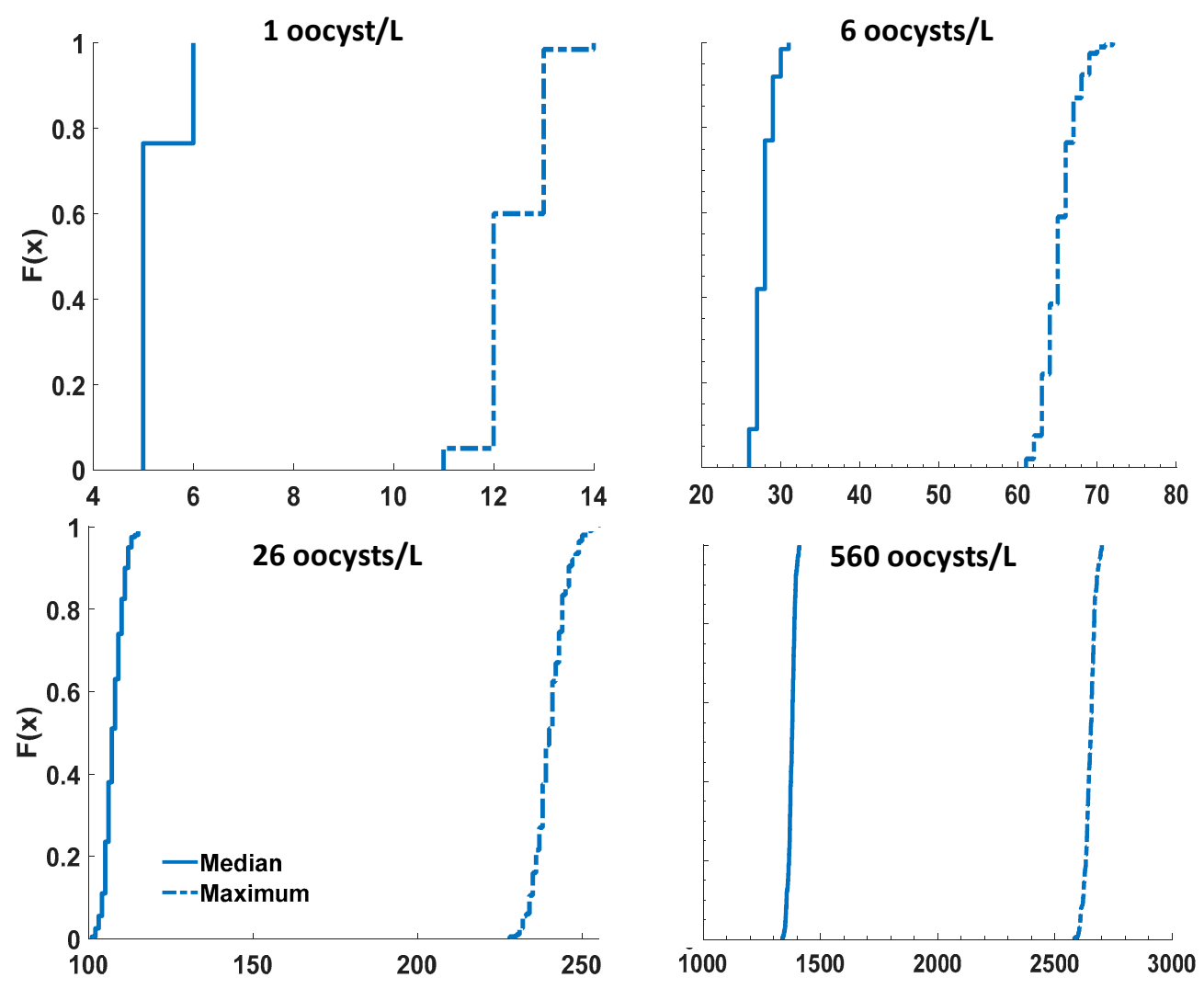

Number of infected people

Figure 4. Number of infected people corresponding to median and maximum infection risks resulting from a 24-h depressurization; 200 Monte Carlo simulations (consumption events) for each Cryptosporidium concentration: 1, 6, 26, and 560 oocysts/L; number of infected people corresponds to the cumulative dose over four days of observation; $\mathrm{F}(\mathrm{x})$ : probability that the median/maximum number of infected people will be less than or equal to $x$.
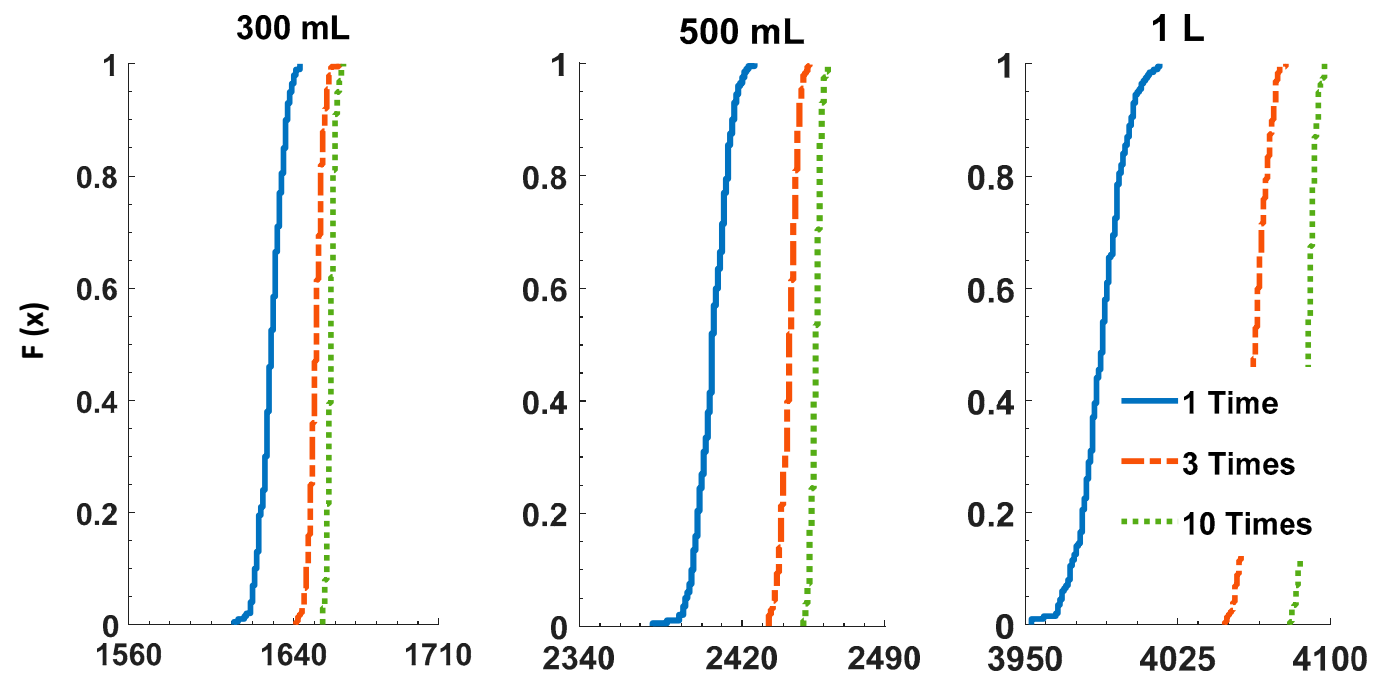

Number of infected people (median infection risk)

Figure 5. Impact of consumption volumes and number of glasses per day on the number of infected people corresponding to median infection risk over a four day-period; Cryptosporidium concentration = 560 oocysts/L; the $\mathrm{x}$-axis scale is the same between the plots (150 people). 
Duration. Shorter duration PDCs can take place in real networks because of WTP shutdowns, pipe breaks or fire flows. The cumulative probability distribution of the number of infected people for 200 random consumption behaviors is shown for different durations of PDCs: 1, 10, and $24 \mathrm{~h}$ (Figure 6). In all scenarios, the timing of the event was adjusted so that the network experienced low/negative pressures at the peak consumption time (i.e., 19:00) of the first day. A significant dependence of the infection risk with the intrusion duration was observed: a lower maximum number of infected people (84) was observed for a 1-h intrusion compared to 502 and 1410 for 10 and $24 \mathrm{~h}$ intrusion events, respectively.

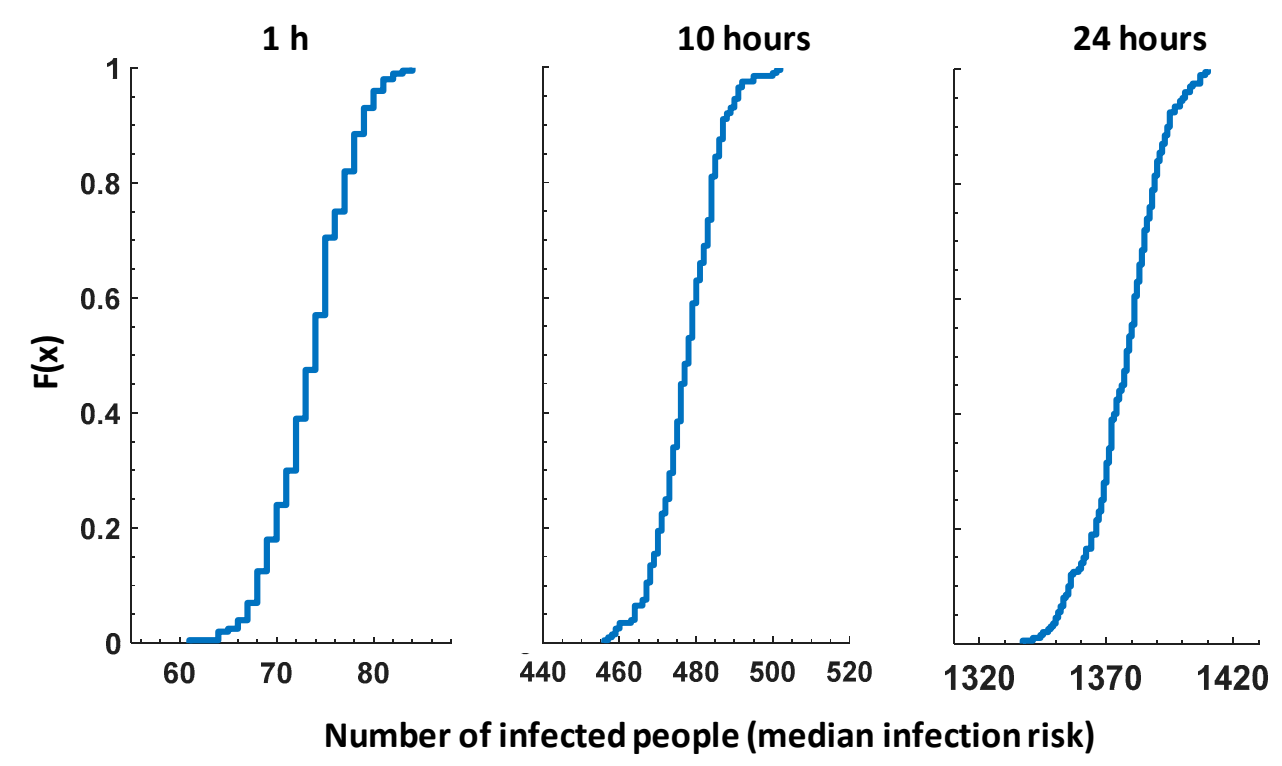

Figure 6. Comparing the probability distribution of the number of infected people over a four-day period for 200 Monte Carlo simulations for each duration of PDCs: 1, 10, and $24 \mathrm{~h}$; Cryptosporidium concentration in sewage $=560$ oocysts $/ \mathrm{L}$.

Spatial distribution of nodal infection risk. Besides the number of infected people under PDCs, the temporal and geographical distribution of infection risk is also essential in defining appropriate preventive/corrective actions. In this regard, the probability of infection of the individuals who were assigned to the same node were summed up to predict the nodal risk. Figure 7 shows the spatial distribution of risk for above-mentioned scenarios corresponding to the consumption events with the maximum number of infected people $(\mathrm{F}(\mathrm{x})=1$ in Figure 6). As shown, with increasing duration of intrusion event, not only the nodal risks are were, but also larger areas were at risk.

Daily risk for the 1-h event with daily demand patterns. For the prior analyses, demand was considered constant during the day and equal to the peak hour demand (i.e., 19:00) in the hydraulic model. The reason is that adjusting different intrusion volumes and nodes at each hour of the duration of PDCs using PDA would be computationally intensive. However, we investigated a $1 \mathrm{~h}$ PDCs/intrusion using the daily water consumption pattern in the hydraulic model to assess its impact on the infection risk. Over four days of observation, the maximum number of infected people increased to 99 (Figure S3) with demand patterns compared to 84 with a constant demand in the hydraulic model (Figure 6, $1 \mathrm{~h}$ ). 

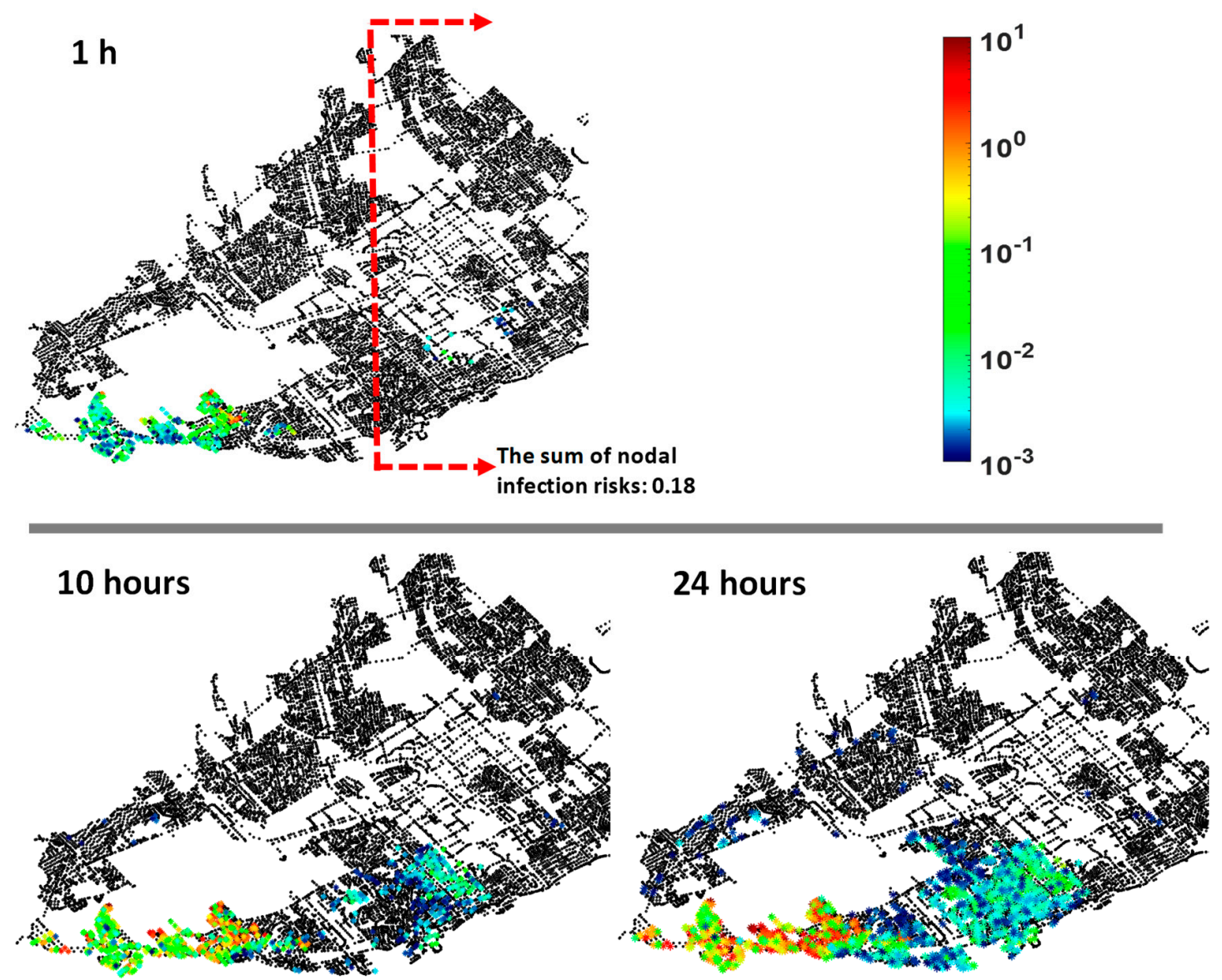

Figure 7. Spatial distribution of nodal risks for three durations of PDCs: 1, 10, and $24 \mathrm{~h}$; Cryptosporidium concentration in sewage $=560$ oocysts $/ \mathrm{L}$; nodes with an infection risk below $1 \times 10^{-3}$ are drawn in black; infection risks corresponding to consumption events with $\mathrm{F}(\mathrm{x})=1$ (Figure 6) are illustrated.

Figure 8 illustrates the daily probability of the number of people infected by Cryptosporidium according to different consumption behaviors for the day that intrusion occurred (at 18:30) and the three days post-intrusion. The day after the event, the maximum number of infected people was reduced by $59 \%$ as compared to the event day. It indicates that, over time, the contaminated water left the network as large volumes of water were used for purposes other than drinking, such as toilet flushing and industrial usage. The maximum numbers of infected people for Days 1-4 were 71, 29, 3 and 1 , respectively.

For Days 1-4, the total nodal risk corresponding to the consumption event with the maximum number of infected people $(\mathrm{F}(\mathrm{x})=1$ in Figure 8$)$ was estimated, and the spatial distribution is plotted in Figure 9. The number of nodes at high risk decreased from Day 1 to Day 4 as well as the extent of the areas at risk. At the end of the first day, when the intrusion ended, the nodal infection was $\leq 1 \times$ $10^{-7}$ at 29,754 nodes and higher than $1 \times 10^{-4}$ at 123 nodes. Only 16 of the nodes showed total nodal risks equivalent to more than one person. On Day 2, the total number of infected people through the whole network decreases to 29 compared to 71 for Day 1, but the number of nodes with an infection risk $\leq 1 \times 10^{-7}$ was lower compared to Day 1 . The reason is that Cryptosporidium oocysts reached more nodes in the network on Day 2, but at lower concentrations as the ingress volume became diluted and flushed out. On Day 2, the nodal infection risk was more than one only at four nodes. On Days 3 and 4 , the nodal infection risk was below one for all the nodes. 

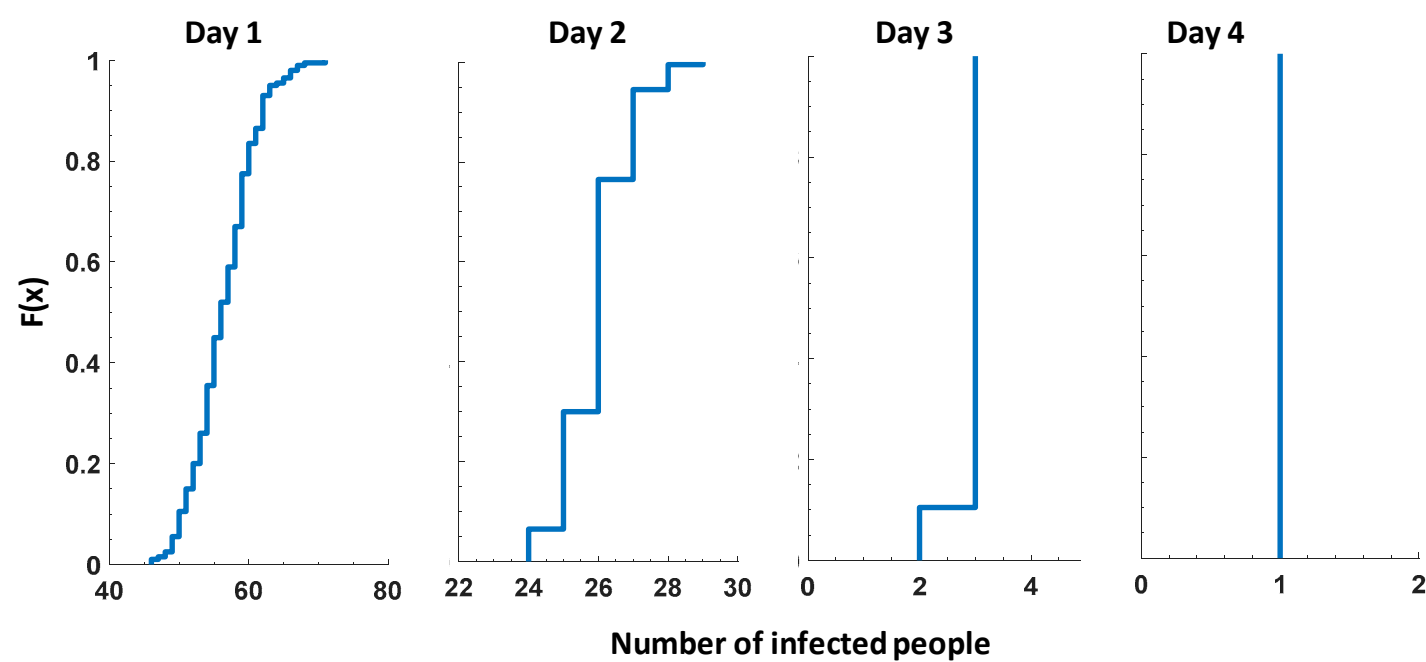

Figure 8. Number of infected people corresponding to median infection risk for Days 1-4 for the scenario of $1 \mathrm{~h}$ of PDCs with daily consumption patterns; $\mathrm{C}_{\text {out }}=560$ oocysts $/ \mathrm{L} ; 200$ Monte Carlo simulations (consumption events) every day.

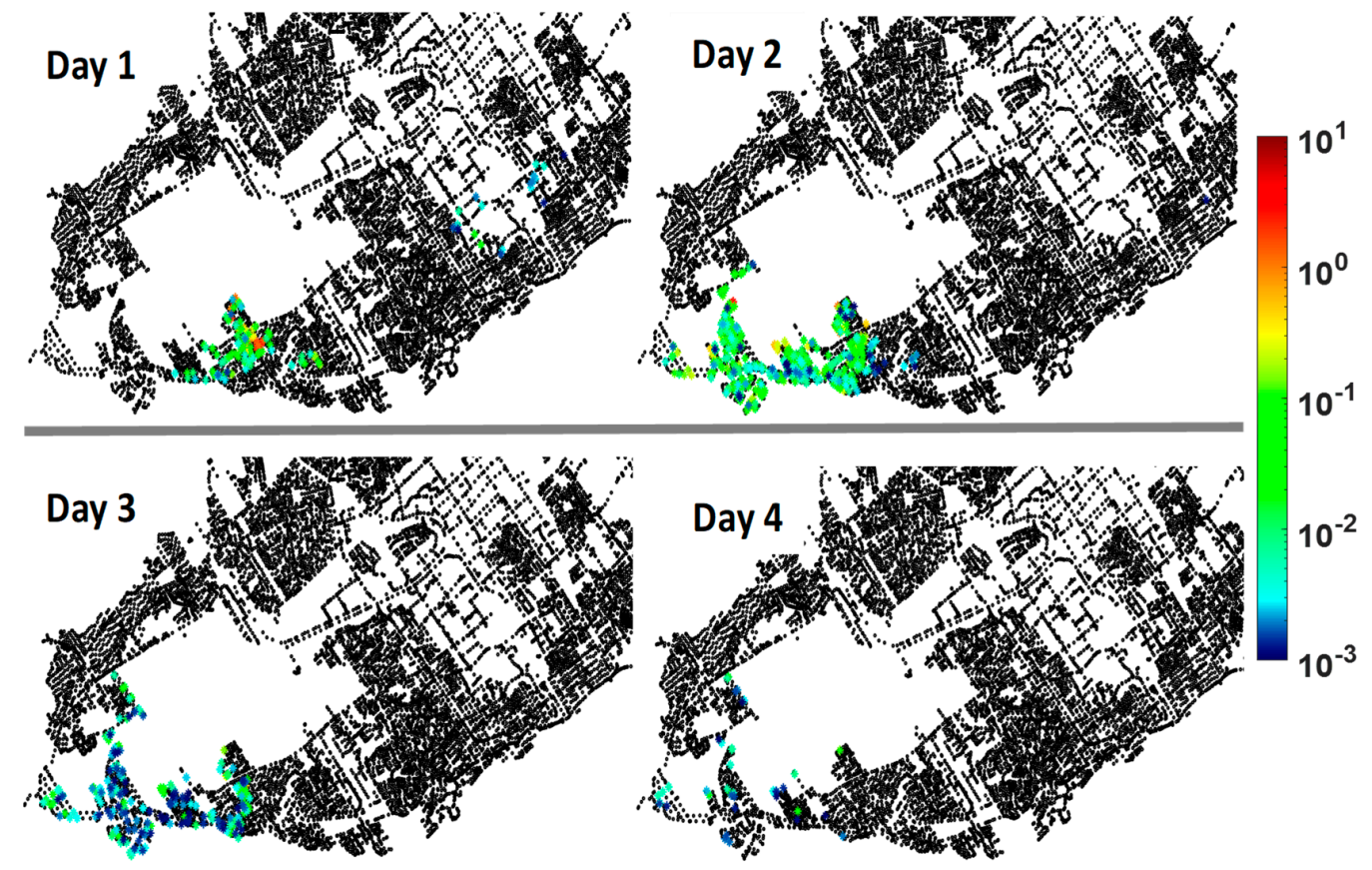

Figure 9. Spatial distribution of nodal risk; Days 1-4 for the scenario of $1 \mathrm{~h}$ of PDCs with daily consumption patterns; $\mathrm{C}_{\text {out }}=560$ oocysts $/ \mathrm{L}$; nodes with infection risk below $1 \times 10^{-3}$ are drawn in black; infection risks corresponding to consumption events with $\mathrm{F}(\mathrm{x})=1$ (Figure 8) are illustrated.

Impact of demand satisfaction ratio on risk. In all simulations, when the DSR (pressure $\leq 0$ ) became zero at a node, the kitchen tap use was set to zero. To study the influence of the DSR (shown in Figure $2 \mathrm{~b}$ ) on the risk, the situation where no consumption happened at nodes with a DSR less than $5 \%$ was also modeled (Figure 10). For this investigation, the number of infected people following a 1-h PDCs/intrusion was computed on the day that intrusion occurred. As expected, the number of infected people decreased when the consumption only occurred at the nodes with a DSR $\geq 5 \%$ during low/negative pressure conditions (Figure 10). 


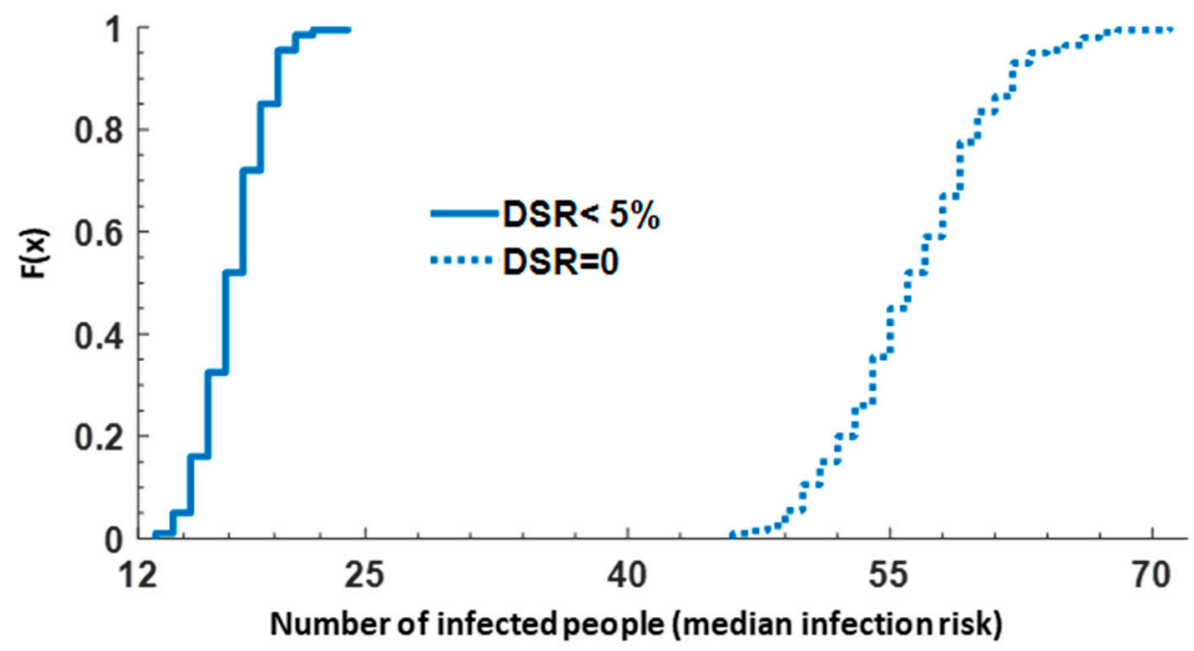

Figure 10. Probability distributions of the number of infected people during the first day of simulation when people with a DSR null and less than 5\% do not drink water from tap; 200 Monte Carlo simulations for each scenario; $C_{\text {out }}=560$ oocysts $/ \mathrm{L}$ with $1 \mathrm{~h}$ of PDCs with daily consumption patterns.

\section{Discussion}

Impact of event duration on the spatial distribution of risk in the network. During an intrusion event, the intrusion risk was determined by several factors such as the intrusion volume, pathogen concentration, network hydraulics, fate and transport of the contaminants and consumers' behavior. The volume of contaminated water entering the network is a function of the duration of the event. For the events with 1, 10 and $24 \mathrm{~h}$ of sustained depressurization, the estimated intrusion volumes through all leak openings were $0.8,8$ and $19 \mathrm{~m}^{3}$, respectively. Using the orifice equation, some studies have produced estimates of the intrusion volumes through leakage points for transient PDCs $[1,13,22]$. The total intrusion volumes resulting from a momentary pump shutdown for different intrusion conditions through leakage orifices and submerged air vacuum valves (AVVs) ranged from 10 to $360 \mathrm{~L}$ in the same network [22]. In contrast, these authors also showed that the maximum volume entering through a single submerged AVV during a transient could be about 95 times larger than the maximum volume entering through a single leakage orifice ( $227 \mathrm{~L}$ versus $2.4 \mathrm{~L}$ ). In their study, the modeled intrusion volume was driven by the global leakage rate ( $5 \%$ versus $40 \%)$ and pressure differential. However, as these authors also stated, the orifice size at a given node should reflect the local leakage demand. Using Monte Carlo simulations, Gibson et al. [23] investigated the impact of head differences, diameter of orifices, pipe age (number of holes), and low pressure duration on the intrusion volumes during transient negative pressure events. For a 25-year-old pipe, the probability of an intrusion volume greater than $10 \mathrm{~L}$ was low (1\%), while it increased to $70 \%$ for a 150 -year-old pipe.

In the current study, the orifice size at each node was considered proportional to the assigned nodal leakage demand in the calibrated model under normal operating conditions as described in detail by Hatam et al. [27]. In the test DS, leakage demand reflects the state of pipes; older areas with aging cast iron being the dominant pipe material has higher leakage and thus offers more potential entry points for contaminated water. In this study, the effect of soil-leak interactions was ignored and the exponent in the orifice equation was considered equal to the theoretical value (0.5) that is valid for fixed leak openings. It was confirmed that the variation of the area of round hole with pressure is negligible and therefore the leakage exponent was close to $0.5[28,29]$. However, for longitudinal slits that have large head-area slope, a modified orifice equation should be used in which the leakage exponent can change within 0.5 to 1.5 [30].

In this study, long durations of PDCs were considered as opposed to relatively short durations of low and negative pressures. Sustained PDCs are reported in the literature due to transmission main repairs $[12,31]$ and can happen during power outages. This type of event may be less frequent 
than transient pressure fluctuations, but of graver consequences, as shown by the potentially larger intrusion volumes. The duration of transient negative or low pressures is a key factor affecting the virus infection risks estimated by QMRA [13-15]. As expected, for the simulated sustained PDCs, the number of infected people for the three different intrusion durations showed strong dependency on the intrusion duration (Figure 6), as it determines the total amount of Cryptosporidium oocysts introduced into the network. The maximum number of infected people was reduced to less than half when the intrusion duration decreased from $24 \mathrm{~h}$ (1410) to $10 \mathrm{~h}$ (502), and even more so if the event only lasted $1 \mathrm{~h}(84)$. Our results are in agreement with those of Schijven et al. [20], who used QMRA to investigate the impact of intentional contamination. Exposed persons were increased by $2-3$ folds when the duration of the injection of contaminants increased from 10 to $120 \mathrm{~min}$.

More importantly, in this study, we showed that the duration determined the areas with high pathogen concentrations corresponding to a potentially significant infection risk. The geographical distribution of the nodal risk shown in Figure 7 emphasizes the importance of considering the duration of PDCs/intrusion when issuing sectorial boil water advisories (BWA) as well as other preventive/corrective actions. For 24 and $10 \mathrm{~h}$ intrusion events, the zones at risk were more or less the same with different risk levels. However, for a much shorter duration of intrusion $(1 \mathrm{~h})$, the zones at elevated risk were significantly reduced (Figure 8 ). The arbitrary cutoff line in Figure 8 can be used to compare the summation of the total risks at nodes in different zones affected by contaminated ingress water. On its right side, a very small cumulative risk of 0.2 infection for the $1 \mathrm{~h}$ intrusion was observed; this risk increased to 1.4 and 3.5 for the intrusion events of 10 and $24 \mathrm{~h}$, respectively. These values include all low nodal risks $\left(\leq 1 \times 10^{-3}\right)$, which are not plotted in Figure 7 for clarity.

Concentration of Cryptosporidium in ingress water. There are scarce data on the actual concentrations of pathogens in ingress water. Concentrations of pathogens in ingress water could range from those found in wastewater, representing a high-risk scenario of ingress directly from undiluted sewage [26], to the much lower concentrations measured in trench water, urban groundwater or runoff [32,33]. The number of infected people increased from 6 to 1410 when Cryptosporidium concentrations increased from 1 to 560 oocysts/L (Figure 4, median) for the worst-case consumption event (out of 200) $(\mathrm{F}(\mathrm{x})=1)$. In agreement with our results, the contaminant concentration outside the pipe ranked among the top factors in previous QMRA studies $[13,15,18,34]$. When using the maximum dose-response relationship rather than the median relationship to account for uncertainties, the maximum number of infected people increased about two folds (Figure 4). The magnitude of differences between the median and maximum dose-response relationships is a critical factor to consider as recent evidence suggests that even higher dose-response values for $C$. hominis should be considered $[2,25]$. Therefore, both the concentrations and the selection of the dose-response will contribute to uncertainty [2].

Consumption behavior. Standard QMRA models usually consider only one consumption event per day $[14,15]$ or a constant volume of consumption per day for every person at fixed hours $[16,21]$. For the $24 \mathrm{~h}$ scenario, the amount of water consumed daily from the kitchen tap had a huge impact on the maximum number of infected people, with decreases of $\sim 40 \%$ and $60 \%$ when consumption was reduced from a baseline of $1 \mathrm{~L} /$ day to $500 \mathrm{~mL} /$ day and $300 \mathrm{~mL} /$ day, respectively. The model was also sensitive, but to a lesser degree, to the number of glasses per day for a fixed volume (Figure 5). Increasing the number of glasses per day from 1 to 10 increased the overall infection risk (by up to 2\%) for the 24-h scenario. This rise was more pronounced for larger consumption volumes (Figure 5). Impact of the number of glasses per day was most noticeable when switching from a single consumption event to 3 or 10 consumption events. Blokker et al. [18] and Van Abel et al. [35] also observed that three ingestion volumes per day result in higher numbers of infected people compared to only one withdrawal of the total volume per day.

Several studies have investigated and integrated probabilistic models to better represent the consumers' behavior into QMRA models, including PDFs of volume of unboiled tap water, number of glasses per day, volume per glass, timing of consumption, and household water usage $[17,18,20,36]$. 
Blokker et al. [18] fully integrated consumers' behavior using a Poisson distribution for the number of glasses per person per day and a lognormal distribution for the ingested volume per glass and the kitchen tap use. This model was applied to investigate various scenarios of fecal contamination resulting from DS repairs and the potential for preventive actions to mitigate risks of infection. In this study, we used the Blokker model to investigate accidental intrusion due to sustained low/negative pressure event of various durations, adding 200 simulations to quantify the range of risks corresponding to different consumers' behavior. The differences between the numbers of infected people for minimum $(\mathrm{F}(\mathrm{x})=0)$ and maximum $(\mathrm{F}(\mathrm{x})=1)$ probabilities in Figure 8 reveal the potential impact of consumers' behavior for a specific event. The ranges were widest for the first day (from 71 to 46 people, 35\% reduction) compared to the following days. The variations observed were less important in the scenarios of 10 and $24 \mathrm{~h}$ (Figure 6). Understanding the uncertainty associated with a combination of plausible behaviors appears important.

Impact of daily demand. The diurnal consumption patterns result in variable intrusion volumes and numbers of intrusion nodes during different hours of the day because of the variations in nodal pressure values. In this study, the demand was set to peak hour demand, which could lead to overestimation of intrusion volumes if system pressure was not decreased for night flows. On the other hand, fixed peak water demand overestimated the flushing of contaminants from the network by leakage, commercial, industrial, institutional demands, etc. during periods of low human consumption, resulting in an underestimation of the risk. With the scenario of $1 \mathrm{~h}$ PDCs/intrusion which incorporates daily demand patterns in the hydraulic model, it was shown that the underestimation was about $15 \%$, which we consider to be acceptable (Figure 6 compared to Figure S3).

Integrating demand availability from PDCs. The novelty of this work lies in the coupling of the PDA and QMRA. Unlike DDA, PDA permits identification of areas with demand shortage, allowing for more realistic estimations of consumption based on water availability at the tap during pressure losses. For example, consuming at a DSR of $5 \%$ and less would mean that the filling time would increase by more than 20-fold. As shown on Figure 10, the number of infected people on Day 1 decreased sharply from 71 to $24(65 \%)$ if only consumers at nodes with DSR $>5 \%$ during low/negative pressures were considered. It should be noted that limitations to consumption only occur during the low-pressure conditions. Furthermore, the extent of these differences depends on the consumption time, and the duration and timing of the event. The results shos that restricting drinking water consumption during periods of low or intermittent flow would greatly reduce risks. Therefore, utilities and health authorities could consider educating people not to consume water during these periods of low flow. Further study is needed to define a minimal DSR criteria based on the amount of reduction in infection risk.

Implication for risk management. The nodal risks considered the contaminant transport in the network and the probability of coincidence of passage of contaminants at the tap and consumption. However, the spatial and temporal distribution of total nodal risks also reflected the distribution of the population between nodes (Figures 7 and 9). The areas in which to issue a BWA, and those where corrective actions (e.g., flushing) would be effective, can be determined using nodal risk values in reference to an acceptable risk level.

QMRA models have been used to evaluate the efficacy of different mitigation strategies such as BWAs, flushing, and disinfection for reducing the infection risk after main break repairs/transient pressures $[14,18,34]$. Yang et al. [34] showed that flushing at $>0.9 \mathrm{~m} / \mathrm{s}$ reduced infection risks by $2-3 \operatorname{logs}$ for norovirus, E. coli O157:H7 and Cryptosporidium. For viral and bacterial pathogens, disinfection with a CT of at least $100 \mathrm{mg} \cdot \mathrm{min} / \mathrm{L}$ using free chlorine was required after flushing to decrease the risk below the USEPA yearly microbial risk target value $\left(1 \times 10^{-4}\right)$ [37]. Issuing a system-wide BWA that decreased by $80 \%$ the average number of glasses of unboiled water consumed led to a four-fold reduction in the number of infected people [18].

Estimating the daily risk, instead of the event risk, after an intrusion event can guide risk management decisions. The spatial distribution of risk as shown in Figure 9 is a key factor to define 
the boundaries and duration of sectorial BWAs. Figures 8 and 9 show the contribution of each day to the total event risk over the four-day period. Notably, for the 1-h intrusion, delaying necessary preventive/corrective actions up to $5 \mathrm{~h}$ from the start of the intrusion may result in the infection of up to 71 people. After that 5-h mark, a BWA or other preventive/corrective actions would still offer protection for about 33 additional people (sum over the three following days). The reduced benefit of late interventions on the fourth day was evident with only one equivalent infection prevented. Timely response to sustained PDCs is therefore essential and can be achieved by improving sampling strategies using enhanced numerical model [27] and equipping the DS with multiple online pressure sensors and water quality sensors. The duration of the BWA could be adjusted depending on the corrective actions implemented to meet the acceptable risk level for an event.

Figure 11 offers insights into whether pressure during PDCs can be used to determine areas to target for preventive/corrective actions. Pressure during the PDCs determine the extent of intrusion. However, whether contaminants will travel from low-pressure nodes to higher pressure nodes (based on pressure during PDCs) is determined by water paths during normal and PDCs. This was clearly illustrated by the fact that, for the 1-h PDCs, consumption of tap water at nodes other than negative pressure nodes resulted in 63, 28,3, and 1 infected people on Days 1-4, respectively. This showed that the benefits of avoiding consumption at negative nodes (based on the pressure values under PDCs) after the PDCs was limited, as these values for the whole network, including negative nodes, were $71,29,3$ and 1, respectively. Even with a pressure criterion of $15 \mathrm{~m}$, the number of infected people on Day 2 would be significant (6) (Figure 11). These results are consistent with the study by Hatam et al. [27] who showed that $E$. coli can be transported to higher pressure zones (up to $\sim 40 \mathrm{~m}$ ) in the absence of disinfectant residuals during a 5-h PDCs/intrusion. Our results emphasize that issuing sectorial BWAs based only on pressure is not adequate to protect the population against infection, even for the scenario of 1-h PDCs/intrusion with a high Cryptosporidium concentration (560 oocyst/L). The simulation of the fate and transport of contaminants is necessary to define an effective sectorial BWA.

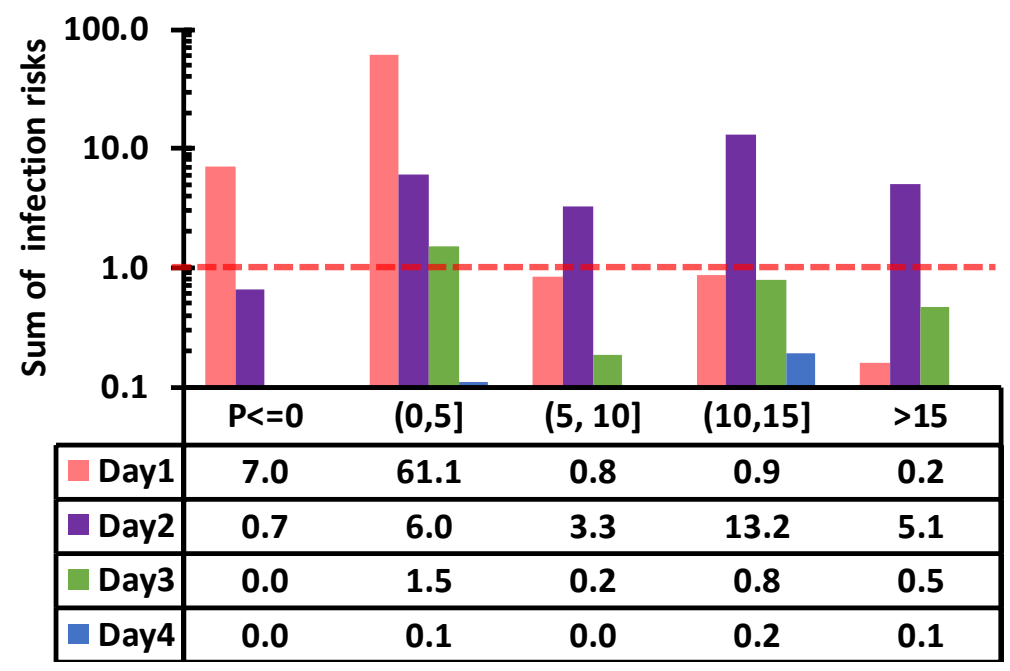

Figure 11. Number of infected people for different pressure $(\mathrm{P})$ ranges (based on the pressure values under PDCs) on Days 1-4; Infection risks corresponding to the consumption event with $\mathrm{F}(\mathrm{x})=1$ (Figure 8) are illustrated. The event starts at 18:30 on Day 1 for a duration of $1 \mathrm{~h}$. Daily patterns in the hydraulic model.

In future work, reporting the hourly risk, instead of the daily risk, could be helpful to utilities to define preventive/corrective actions and timely response. In this study, the PDCs occurred at 18:30 on Day 1 , therefore some of the daily demands were already satisfied before the intrusion event. The timing of the event impacts the infection risk, which needs to be investigated in future studies. Blokker et al. [18] showed limited effect for timing of repairs. 
Although the field validation of the transport of pathogens and indicators appears desirable, it is however not feasible to conduct in complex operating distribution systems. Such validation would require extensive monitoring during intentional extended loss of pressure events and monitoring of infections by an epidemiological investigation that utilities and health authorities will not allow. The conservative modelling presented in this study nevertheless demonstrates the value of numerical tools combined to QMRA to quantify risk and assist utilities and regulators.

\section{Conclusions}

- An approach is proposed to couple QMRA and water quality calculations based on pressure-driven hydraulic analysis to assess the infection risk under sustained low/negative pressure events, causing accidental intrusion of potentially contaminated water surrounding the pipes. The intrusion volume at potential intrusion nodes is adjusted for nodal pressure and pipe state (age and material) using leakage demand.

- By implementing PDA, the pattern of kitchen tap use was dynamically modified to include the impact of demand availability during PDCs in the analysis. During the PDCs, using a higher critical value of the DSR ( $5 \%$ instead of no demand) for drinking water withdrawals led to a significant reduction in the number of infected people ( $65 \%$ on Day 1 of $1-\mathrm{h}$ PDCs). This reduction in infection risk if contaminated water is not consumed should be considered to guide preventive notices. It shows that customers should be advised not to drink water when flow at the tap is low (i.e., it takes much longer time to fill a glass).

- In this work, depending on the pathogen concentration in sewage, the number of infected people changed by 235 -fold, showing the importance of selecting a representative level of contamination in a system. Using raw sewage as the ingress water is a conservative scenario as water surrounding water mains is likely to be less contaminated than sewage.

- Results show that the number of glasses per day (1,3, or 10) was less important than the consumption volume $(300 \mathrm{~mL}, 500 \mathrm{~mL}$, or $1 \mathrm{~L})$ for the scenario of $24-\mathrm{h}$ PDCs.

- The duration of PDCs/intrusion is a decisive factor in determining the infection risk, issuing sectorial boil water advisories and other preventive/corrective actions. Spatial and temporal distribution of nodal risks presented in this study can help to determine the boundaries and duration of sectorial BWAs.

- A fast response by the utility is key to reducing the infection risk by limiting the contamination area. For a 1-h intrusion, delaying $5 \mathrm{~h}$ the necessary preventive/corrective actions from the start of the intrusion may result in the infection of up to 71 people.

Supplementary Materials: The following are available online at http:/www.mdpi.com/2073-4441/11/7/1372/s1, Figure S1: Consumption at kitchen tap use, Figure S2: Distribution of population, Figure S3: Probability distribution of the number of infected people during four days of simulation with daily pattern in the hydraulic model, Figure S4: Spatial distribution of pressure.

Author Contributions: Conceptualization, F.H., M.P., M.B., M.-C.B., and G.E.; Investigation and formal analysis, F.H. and M.P.; Methodology and software, F.H., and M.B.; writing—original draft, F.H.; writing-review and editing, M.B, M.-C.B, G.E., and M.P.

Funding: This research was funded by the NSERC Industrial Chair on Drinking Water at Polytechnique Montréal.

Acknowledgments: The participating utility gratefully provided information of the distribution system model. The authors would like to thank Bentley Systems for providing academic access, with unlimited pipes version, to the utility model.

Conflicts of Interest: The authors declare no conflict of interest. 


\section{References}

1. Kirmeyer, G.J.; Friedman, M.; Martel, K.; Howie, D.; LeChevallier, M.; Abbaszadegan, M.; Karim, M.; Funk, J.; Harbour, J. Pathogen Intrusion into the Distribution System; 90835; American Water Works Association Research Foundation, American Water Works Association and United States Environmental Protection Agency: Denver, CO, USA, 2001; p. 254.

2. World Health Organisation (WHO). Quantitative Microbial Risk Assessment: Application for Water Safety Management; World Health Organisation: Geneva, Switzerland, 2016; p. 204.

3. Rossman, L.A. EPANET 2. User's Manual; EPA 600-R-00-57; National Risk Management Research Laboratory, Office of Research and Development, United States Environmental Protection Agency (USEPA): Cincinnati, OH, USA, September 2000; p. 200.

4. Bashi-Azghadi, S.N.; Afshar, A.; Afshar, M.H. Multi-period response management to contaminated water distribution networks: Dynamic programming versus genetic algorithms. Eng. Optim. 2017, 50, 415-429. [CrossRef]

5. Rasekh, A.; Brumbelow, K. Drinking water distribution systems contamination management to reduce public health impacts and system service interruptions. Environ. Model. Softw. 2014, 51, 12-25. [CrossRef]

6. Zafari, M.; Tabesh, M.; Nazif, S. Minimizing the adverse effects of contaminant propagation in water distribution networks considering the pressure-driven analysis method. J. Water Resour. Plann. Manag. 2017, 143. [CrossRef]

7. Hatam, F.; Besner, M.-C.; Ebacher, G.; Prévost, M. Combining a multispecies water quality and pressure-driven hydraulic analysis to determine areas at risk during sustained pressure-deficient conditions in a distribution system. J. Water Resour. Plann. Manag. 2018, 144, 04018057. [CrossRef]

8. Lindley, T.R.; Buchberger, S.G. Assessing intrusion susceptibility in distribution systems. J. Am. Water Works Assoc. 2002, 94, 66-79. [CrossRef]

9. Craun, G.F.; Brunkard, J.M.; Yoder, J.S.; Roberts, V.A.; Carpenter, J.; Wade, T.; Calderon, R.L.; Roberts, J.M.; Beach, M.J.; Roy, S.L. Causes of outbreaks associated with drinking water in the United States from 1971 to 2006. Clin. Microbiol. Rev. 2010, 23, 507-528. [CrossRef] [PubMed]

10. Viñas, V.; Malm, A.; Pettersson, T.J.R. Overview of microbial risks in water distribution networks and their health consequences: quantification, modelling, trends, and future implications. Can. J. Civil Eng. 2019, 46, 149-159. [CrossRef]

11. Hamouda, M.A.; Jin, X.; Xu, H.; Chen, F. Quantitative microbial risk assessment and its applications in small water systems: A review. Sci. Total Environ. 2018, 645, 993-1002. [CrossRef]

12. Besner, M.-C.; Prévost, M.; Regli, S. Assessing the public health risk of microbial intrusion events in distribution systems: conceptual model, available data, and challenges. Water Res. 2011, 45, 961-979. [CrossRef]

13. Teunis, P.F.M.; Xu, M.; Fleming, K.K.; Yang, J.; Moe, C.L.; LeChevallier, M.W. Enteric virus infection risk from intrusion of sewage into a drinking water distribution network. Environ. Sci. Technol. 2010, 44, 8561-8566. [CrossRef]

14. Yang, J.; LeChevallier, M.W.; Teunis, P.F.M.; Xu, M. Managing risks from virus intrusion into water distribution systems due to pressure transients. J. Water Health 2011, 9, 291-305. [CrossRef] [PubMed]

15. LeChevallier, M.W.; Xu, M.; Yang, J.; Teunis, P.; Fleming, K.K. Managing Distribution System Low Transient Pressures for Water; Water Research Foundation and American Water Works Service Company, Inc.: Denver, CO, USA, 2011; p. 144.

16. Besner, M.-C.; Messner, M.; Regli, S. Pathogen intrusion in distribution systems: model to assess the potential health risks. Proceedings of 12th Annual Conference on Water Distribution Systems Analysis (WDSA), Tucson, AZ, USA, 12-15 September 2010; pp. 484-493.

17. Davis, M.J.; Janke, R. Development of a probabilistic timing model for the ingestion of tap water. J. Water Resour. Plann. Manag. 2009, 135, 397-405. [CrossRef]

18. Blokker, M.; Smeets, P.; Medema, G. Quantitative microbial risk assessment of repairs of the drinking water distribution system. Microb. Risk Anal. 2018, 8, 22-31. [CrossRef]

19. Blokker, M.; Smeets, P.; Medema, G. QMRA in the Drinking Water Distribution System. Procedia Eng. 2014, 89, 151-159. [CrossRef] 
20. Schijven, J.; Forêt, J.M.; Chardon, J.; Teunis, P.; Bouwknegt, M.; Tangena, B. Evaluation of exposure scenarios on intentional microbiological contamination in a drinking water distribution network. Water Res. 2016, 96, 148-154. [CrossRef] [PubMed]

21. Islam, N.; Rodriguez, M.J.; Farahat, A.; Sadiq, R. Minimizing the impacts of contaminant intrusion in small water distribution networks through booster chlorination optimization. Stoch. Environ. Res. Risk Assess. 2017, 31, 1759-1775. [CrossRef]

22. Ebacher, G.; Besner, M.-C.; Clément, B.; Prévost, M. Sensitivity analysis of some critical factors affecting simulated intrusion volumes during a low pressure transient event in a full-scale water distribution system. Water Res. 2012, 46, 4017-4030. [CrossRef] [PubMed]

23. Gibson, J.; Karney, B.; Guo, Y. Predicting health risks from intrusion into drinking water pipes over time. J. Water Resour. Plann. Manag. 2019, 145, 04019001. [CrossRef]

24. Bentley Systems, Incorporated. WaterGEMS V8i Users Manual; Haestad Methods Solution Centre: Watertown, CT, USA, 2014.

25. World Health Organization (WHO). Risk Assessment of Cryptosporidium in Drinking Water; WHO/HSE/WSH/09.04; Public Health and Environment, Water, Sanitation, Hygiene and Health; World Health Organization: Geneva, Switzerland, 2009; p. 134.

26. Payment, P.; Plante, R.; Cejka, P. Removal of indicator bacteria, human enteric viruses, Giardia cysts, and Cryptosporidium oocysts at a large wastewater primary treatment facility. Can. J. Microbiol. 2001, 47, 188-193. [CrossRef]

27. Hatam, F.; Besner, M.-C.; Ebacher, G.; Prévost, M. Improvement of Accidental Intrusion Prediction Due to Sustained Low-Pressure Conditions: Implications for Chlorine and E. coli Monitoring in Distribution Systems. J. Water Resour. Plann. Manag.. submitted.

28. Van Zyl, J.E.; Clayton, C.R.I. The effect of pressure on leakage in water distribution systems. Inst. Civil Eng. Water Manag. 2007, 160, 109-114. [CrossRef]

29. Van Zyl, J.E.; Malde, R. Evaluating the pressure-leakage behaviour of leaks in water pipes. J. Water Suppl. Resear. Technol. Aqua 2017, 66, 287-299. [CrossRef]

30. Van Zyl, J.E.; Lambert, A.O.; Collins, R. Realistic modeling of leakage and intrusion flows through leak openings in pipes. J. Hydraul. Eng. 2017, 143. [CrossRef]

31. Besner, M.-C.; Ebacher, G.; Lavoie, J.; Prévost, M. Low and negative pressures in distribution systems: Do they actually result in intrusion? Proceedings of 9th Annual Water Distribution System Analysis Symposium, ASCE-EWRI World Environmental and Water Resources Congress, Tampa, FL, USA, 15-19 May 2007; p. 10.

32. Ebacher, G.; Besner, M.-C.; Prevost, M. Submerged appurtenances and pipelines: An assessment of water levels and contaminant occurrence. J. Am. Water Works Assoc. 2013, 105, E684-E698. [CrossRef]

33. Besner, M.-C.; Broséus, R.; Lavoie, J.; Di Giovanni, G.; Payment, P.; Prévost, M. Pressure monitoring and characterization of external sources of contamination at the site of the Payment drinking water epidemiological studies. Environ. Sci. Technol. 2010, 44, 269-277. [CrossRef] [PubMed]

34. Yang, J.; Schneider, O.D.; Jjemba, P.K.; Lechevallier, M.W. Microbial risk modeling for main breaks. J. Am. Water Works Assoc. 2015, 107, E97-E108. [CrossRef]

35. Van Abel, N.; Blokker, E.J.; Smeets, P.W.; Meschke, J.S.; Medema, G.J. Sensitivity of quantitative microbial risk assessments to assumptions about exposure to multiple consumption events per day. J. Water Health 2014, 12, 727-735. [CrossRef] [PubMed]

36. Davis, M.J.; Janke, R. Importance of exposure model in estimating impacts when a water distribution system is contaminated. J. Water Resour. Plann. Manag. 2008, 134, 449-456. [CrossRef]

37. National Research Council of the National Academies. Drinking Water Distribution Systems: Assessing and Reducing Risks; The National Academies Press: Washington, DC, USA, 2006; p. 404.

(C) 2019 by the authors. Licensee MDPI, Basel, Switzerland. This article is an open access article distributed under the terms and conditions of the Creative Commons Attribution (CC BY) license (http://creativecommons.org/licenses/by/4.0/). 